\title{
CONDICIONANTES DA TOLERÂNCIA POLIITICA NO BRASIL CONTEMPORÂNEO
}

\author{
Vitor de Moraes Peixoto ${ }^{1}$ \\ Jessica Matheus de Souza ${ }^{2}$
}

\begin{abstract}
Resumo
Este trabalho objetivou a construção de análises a respeito da percepção da economia pessoal e do país pelo cidadão e os impactos da avaliação dela no conjunto de comportamentos individuais conhecidos por tolerância política. Os dados analisados foram extraídos da base do Latin American Public Opinion Project (LAPOP), 2016. A hipótese central do estudo propunha correspondência entre avaliações egotrópica e sociotrópica da economia e grau de tolerância individual, e a mesma não foi comprovada. Porém, foram encontradas variáveis que exercem significativo impacto na tolerância política: foi negativo o antipetismo, idade, vítimas de crimes e religiosos das classificações evangélico pentecostal e protestante tradicional, ou seja, esses são os grupos mais intolerantes. Em contrapartida, maior escolaridade tende a aumentar o grau de tolerância dos indivíduos.
\end{abstract}

Palavras-chave: Tolerância Política. Atitudes Democráticas. Opinião Pública.

\section{Conditioning factors of political tolerance in contemporary Brazil}

\begin{abstract}
This work aimed to build analysis regarding the citizen's perception of personal and national economy and the impacts of its evaluation on the set of individual behaviors known as political tolerance. The analyzed data was extracted from the Latin American Public Opinion Project (LAPOP) database, 2016. The central hypothesis of this study proposed a correspondence between egotropic and sociotropic evaluations of economy and degree of individual tolerance, and it was not proven. However, variables that had a significant impact on political tolerance were found: antipetism, age, crime victims and religion (pentecostal evangelic and traditional protestant classifications) were negative, that is, these are the most intolerant groups. In contrast, higher education tends to increase the degree of tolerance of individuals.
\end{abstract}

Keywords: Political Tolerance. Democratic Attitudes. Public Opinion.

\footnotetext{
1 Professor associado da Universidade Estadual do Norte Fluminense Darcy Ribeiro.

${ }^{2}$ Mestranda em Sociologia Política da Universidade Estadual do Norte Fluminense Darcy Ribeiro.

Contato: jessicamatheus@outlook.com.
} 


\section{Introdução}

Nos últimos anos se fez perceptível uma robusta mudança na política nacional, e um dos fatores alarmantes foram os recorrentes episódios e discursos de intolerância política, especialmente com a corrida presidencial de 2018. Essa intolerância parece ser fomentada por períodos de crise e acirrada disputa política, concomitantemente à queda de confiança nas instituições democráticas, o aumento do apartidarismo (GIMENES, 2017), e antipartidarismo (RIBEIRO, CARREIRÃO, BORBA, 2011). O presente trabalho tem como objetivo compreender os condicionantes da tolerância política, ou intolerância, no ano de 2016, por meio da relação entre os comportamentos de não-aceitação de grupos opositores ou diferentes e as avaliações sociotrópicas e egotrópicas da economia, análise possibilitada por dados do Latinobarômetro.

Dessa forma, a pergunta que se pretende responder é: como visões sobre a economia do país e sobre a própria mobilidade social refletem na maior ou menor propensão do indivíduo a tolerar opiniões e mobilizações de grupos contrários? A hipótese testada é que a variável de tolerância é afetada de acordo com as avaliações individuais da condição econômica pessoal e do país. O argumento é que o efeito da economia no grau de tolerância acontece uma vez que o sentimento de melhora econômica através de mobilidade social se traduz em sentimento que a vida desse indivíduo melhorou, não importa o que os grupos contrários façam.

Assim, condições adversas, como avaliação de piora da economia do país e pessoal, criam condições para que se responsabilize grupos adversários, que se tornam alvos do sentimento de intolerância. Em suma, serão testadas as hipóteses que se referem à sensação e avaliação da economia vivida e a mobilidade social percebida como fatores chaves para a compreensão de mecanismos através dos quais o estado da economia no país se manifesta nas percepções individuais dos cidadãos.

A questão perpassa o tema das transformações sociais, principalmente a mudança valorativa e cultural que se associa a uma maior propensão de instauração ou adesão à democracia (INGLEHART; WELZEL, 2009), assim como reflexões acerca da qualidade da democracia (O'DONNELL; 1998; PZERWORSKI, CHEIBUB, LIMONGI, 2003). Será utilizada também literatura que traz dimensões especificas da política brasileira, aproveitando a expansão dos estudos nacionais sobre atitudes e comportamento eleitoral. Foram consolidadas nos últimos anos redes de pesquisa 
favorecendo estudos sobre a evolução do partidarismo no Brasil, voto partidário e impacto da avaliação econômica sobre o voto (VEIGA, 2011; CARREIRÃO, 2002; NICOLAU, 2011, 2014; RENNÓ, TURGEON, 2016) mobilidade social e voto (PEIXOTO; RENNÓ, 2011), informação e voto (VEIGA, 2007), e, principalmente, cultura e participação política (BORBA, 2005; RIBEIRO; BORBA, 2010; FUKS, 2016; RIBEIRO, CARREIRÃO, BORBA, 2019).

\section{Quadro 1 - Resumo do Desenho de Pesquisa}

\begin{tabular}{|c|c|}
\hline $\begin{array}{l}\text { Questão } \\
\text { de } \\
\text { Pesquisa }\end{array}$ & $\begin{array}{l}\text { Como visões sobre a economia do país e sobre a } \\
\text { própria mobilidade social se refletem na maior ou } \\
\text { menor propensão do indivíduo a tolerar opiniões e } \\
\text { mobilizações de grupos contrários? }\end{array}$ \\
\hline Hipótese & $\begin{array}{l}\text { A avaliação de piora da economia do país e pessoal } \\
\text { cria condições para que se responsabilize grupos } \\
\text { adversários, que se tornam alvos do sentimento de } \\
\text { intolerância. O contrário acontece com uma } \\
\text { avaliação de melhora, que geraria tolerância. }\end{array}$ \\
\hline $\begin{array}{l}\text { Objetivo } \\
\text { Geral }\end{array}$ & $\begin{array}{l}\text { Compreender como as avaliações egotrópicas e } \\
\text { sociotrópicas da economia afetam a tolerância } \\
\text { expressa por grupos discriminados e oposição política. }\end{array}$ \\
\hline Variáveis & $\begin{array}{l}\text { Dependente: tolerância política } \\
\text { Independentes: } \\
\text { - } \quad \text { avaliação egotrópica da economia; } \\
\text { - } \quad \text { avaliação sociotrópica da economía; } \\
\text { - } \quad \text { sexo; } \\
\text { - } \quad \text { religião (católico, protestante tradicional, } \\
\text { evangélico pentecostal, sem religião); } \\
\text { - } \quad \text { anos de escolaridade formal; } \\
\text { - } \quad \text { idade; } \\
\text { - } \quad \text { macrorregião nacional; } \\
\text { - } \quad \text { renda mensal habitacional; } \\
\text { - } \quad \text { mobilidade social; } \\
\text { - } \quad \text { carência de refeição } \\
\text { - } \quad \text { vítima de crime; } \\
\text { - } \quad \text { insatisfação com a vida; } \\
\text { - } \quad \text { desemprego; } \\
\text { - } \quad \text { antipetismo; }\end{array}$ \\
\hline
\end{tabular}

CSOnline - Revista Eletrônica de Ciências Sociais, Juiz de Fora, n. 30 (2019) 


\begin{tabular}{|l|l|}
\hline & $\begin{array}{l}\bullet \quad \text { antipessedebismo; } \\
\text { posicionamento político à direita; } \\
\text { posicionamento político à esquerda. }\end{array}$ \\
\hline $\begin{array}{l}\text { Unidade } \\
\text { de } \\
\text { Análise }\end{array}$ & Indivíduos \\
\hline $\begin{array}{l}\text { Recorte } \\
\text { temporal }\end{array}$ & 2016 \\
\hline $\begin{array}{l}\text { Técnicas } \\
\text { de } \\
\text { análise }\end{array}$ & $\begin{array}{l}\text { Estatística descritiva, comparação de médias, } \\
\text { regressão linear de mínimos quadrados ordinários } \\
\text { (MQO) }\end{array}$ \\
\hline $\begin{array}{l}\text { Fonte } \\
\text { dos } \\
\text { dados }\end{array}$ & $\begin{array}{l}\text { The Americas Barometer by the Latin American Public } \\
\text { Opinion Project (LAPOP), www.LapopSurveys.org }\end{array}$ \\
\hline
\end{tabular}

\section{Teoria da modernização e surgimento dos valores pós-modernos}

Destarte, essa discussão pode ser contextualizada a luz da teoria da modernização apresentada por Inglehart e Welzel (2005), segundo a qual o desenvolvimento socioeconômico daria vez a um conjunto de valores pós-materialistas, provocando profundas alterações no campo religioso, no mundo do trabalho, nas relações de gênero, nas normas sexuais e na atividade política. Essa mudança de valores promove pressões cada vez maiores para 0 estabelecimento da democracia, em países de regime autoritário, ou o aprofundamento dela, em países em fase de consolidação do regime democrático. Assim, a linha de raciocínio coloca o desenvolvimento econômico como propulsor de uma mudança cultural que, entre outros fatores, traz uma valorização da democracia, sistema que melhor representa a nova cultura, que busca a igualdade, liberdade e autonomia individual.

Para Inglehart (2012) a mudança de valores nas sociedades pósindustriais se fundamenta na hipótese que os indivíduos perseguem vários objetivos em ordem hierárquica, o que justifica a máxima atenção às necessidades consideradas mais importantes. Em sua análise sobre a mudança de valores da população na Europa, ele destaca o fator intergeracional que consta nas condições materiais de criação das gerações, que passa do estágio de priorização das necessidades materiais básicas a outro patamar. As populações das sociedades ocidentais, segundo ele, ultrapassaram este estágio 
e foram socializadas em um período de afluência sem precedentes, tomando agora a segurança econômica como garantida.

Assim os antigos valores estão mudando em direção previsível em medida que o desenvolvimento socioeconômico ocorre, para uma cultura emancipatória com novos padrões valorativos. O novo conjunto de valores tem importantes consequências em relação à forma com que as sociedades são governadas, na medida em que a mudança cultural estimula demanda por maior igualdade de gênero, liberdade democrática e boa governança. Os valores de massa desempenham papel fundamental no surgimento de instituições democráticas.

A teoria apresentada por Inglehart e Welzel (2005) considera o impacto do desenvolvimento socioeconômico e a resistência da herança cultural de uma sociedade, afirmando uma mudança sociocultural não linear. Após a industrialização, que causou racionalização secularização e burocratização, ocorre a ascensão da sociedade do conhecimento, que coloca outro conjunto de valores, suscitando ênfase cada vez maior na autonomia individual, livre escolha e auto expressão. Os valores emergentes dão origem a um processo de desenvolvimento humano que caminha em direção a uma sociedade humanística, que preza pela emancipação humana.

Quando as sociedades atingiram maior patamar de riqueza, os valores se deslocam para o exercício da imaginação, tolerância, valores ecológicos, livre escolha, bem-estar e valores de auto expressão. Dessa forma, o processo de modernização socioeconômica estimula a formação de novos padrões valorativos, promovendo uma mudança emancipatória de valores, com a emergência dos valores cívicos, liberais e de auto expressão.

[...] uma cultura humanística - que enfatiza valores de auto-expressão - propaga-se por todos os grandes domínios da vida, ajudando a dar uma nova forma a normas sexuais, papeis de gênero, valores familiares, religiosidade, motivações para o trabalho, relação das pessoas com a natureza e com o meio ambiente, e suas atividades comunitárias e participação política. A crescente valorização da autonomia humana é evidente em todos esses domínios, transformando o tecido das sociedades contemporâneas. [...] Papéis de gênero, orientações religiosas, padrões de consumo habito de trabalho e comportamento eleitoral se tornam, cada vez mais, questões de escolha individual (Inglehart, Welzel, 2005, p. 20). 
A modernização socioeconômica gera as capacidades objetivas que possibilitam a escolha autônoma para cada vez mais pessoas, e os valores de auto expressão levam com que essas exijam a liberdade de escolha, a qual é permitida pelos direitos assegurados por instituições democráticas. Essa mudança de valores promove pressões cada vez maiores para 0 estabelecimento da democracia.

De acordo com os autores, os valores de auto expressão não necessitam de um regime democrático prévio para aflorar, podendo surgir em regime autoritário, causando assim uma demanda em massa por um regime democrático, ou uma democracia mais eficiente, no caso de regimes democráticos de baixa qualidade. A respeito da herança cultural, os autores relatam que embora os valores possam mudar, eles continuam a refletir a herança histórica de uma sociedade; a mudança cultural é dependente da trajetória.

A teoria da modernização é elaborada no contexto das nações pós-industriais, por isso é cabível o estudo da aplicabilidade de seus conceitos e previsões nos casos de jovens democracias com problemas materiais e econômicas pendentes, com o caso brasileiro. Assim existe a indagação sobre a transposição do modelo de Inglehart e Welzel para países latino-americanos. Por isso, são analisados a seguir trabalhos acerca da percepção da democracia entre os brasileiros tanto em seu caráter normativo e quanto funcionamento prático, bem como a temática do pensamento autoritário e a possibilidade de sobrevivência de valores autoritários que se originaram durante a ditadura militar.

\section{Tolerância política}

A tolerância envolve uma atitude que se encontra entre a aceitação absoluta e a oposição imoderada (Scanlon. 2009). Destarte, é necessária ao regime democrático uma vez que a democracia se define como a forma de governo que combina participação política e contestação pública (Ribeiro, Borba. 2010), sem divergência de posições políticas e tolerância a essa divergência $\circ$ regime perde suas dimensões principais. A relevância de empreender uma investigação sobre a tolerância no regime democrático se dá especialmente no momento que o acirramento dos conflitos políticos extrapola do parlamento para atingir às ruas. 
A literatura sobre tolerância política coloca sua importância ao regime democrático na medida que faz parte do grupo de valores que permite o jogo pacífico pelo poder. $O$ indivíduo tolerante respeita os resultados do jogo mesmo que sejam diferentes do que queria; confiando que o governo não vai ser desleal mesmo quando está ocupado por seus adversários, esperando sua vez de ter o poder. As pessoas respeitam a validade de ideias e interesses opostos aos seus e que pessoas diferentes devam ter direitos (Pzerworski, Cheibub, Limongi, 2003).

O tema é abordado na obra "Como as Democracias Morrem" (Levitsky, Ziblatt, 2018) no que concerne a tolerância mútua entre os partidos. Tolerar o partido rival significa que, enquanto seus jogadores jogarem pelas regras institucionais, deve-se aceitar seu direito de existir, assim como competir pelo poder e eventualmente, governar. Dessa forma, se aceita os rivais políticos como legítimos, cidadãos decentes e patrióticos, e por mais que se considere as ideias opostas como incorretas, elas não são vistas como ameaça existencial. Ou seja, os partidos "concordam em discordar".

Os autores relatam que em um cenário onde as normas de tolerância mútua são frágeis os adversários são encarados como ameaça perigosa, e assim muito se tem a temer caso o partido rival seja eleito; podem ser considerados todos os meios necessários para evitar que esse mal ocorra. Assim, a democracia é posta em risco pela utilização de medidas autoritárias para neutralizar a ameaça, políticos considerados subversivos ou criminosos podem ser presos e governos podem ser derrubados. A ideia de que os partidos políticos que se opõe não precisam ser inimigos pode parecer uma ideia óbvia, porém, convém manter em mente que durante a maior parte da história a oposição ao grupo no poder era considerada traição. A tolerância mútua passa a existir com o amadurecimento de certas democracias e não é inerente a todas elas.

Diferentemente da obra anteriormente citada, a tolerância abordada nesse trabalho é a demostrada pelos eleitores, tendo como alvo os partidos ou filiados a eles. A compreensão da evolução da tolerância política é buscada através da relação entre os comportamentos de não-aceitação de grupos opositores ou diferentes com as avaliações sociotrópicas e egotrópicas da economia. Parte do pressuposto que entre os atores políticos da elite a intolerância é um fato perceptível nos discursos, nas campanhas, e nas bandeiras eleitorais. $O$ que este artigo pretende testar refere-se à intolerância ao nível dos eleitores. A hipótese é 
que a tolerância se torna frágil em situações econômicas adversas, assim ocorre a culpabilização do adversário político ou dos grupos desgostados, que são vistos como uma ameaça maior.

\section{Mobilidade social e atitudes políticas}

Rennó e Turgeon (2016) têm como foco o fenômeno da mobilidade social e seus desdobramentos nas atitudes políticas da população brasileira, abordando as diferentes hipóteses levantadas pela literatura especializada e testando-as utilizando os dados do Barômetro das Américas do ano de 2012. Os autores partem de uma revisão da literatura que abarca classes sociais e psicologia política para discorrer sobre as possíveis diferenças comportamentais entre diferentes classes sociais, envolvendo também padrões de mobilidade social. A literatura nacional aponta as implicações políticas do surgimento de uma nova classe média no Brasil, que traria mudanças na percepção política e social da população. A literatura internacional coloca as classes intermediárias e a camada em ascensão como potencializadores da moderação de conflitos sociais e tolerância. Destarte esses setores são associados a uma postura mais aberta, tolerante e moderada.

Foram operacionalizados os dados considerando os conceitos de classe social, mobilidade, não-opiniões, extremismo de atitudes, heterogeneidade atitudinal e tolerância. $O$ critério utilizado para definir a colocação dos indivíduos nas categorias foi a mensuração de classe social com base em bens. Dividiu-se a população nas classes: baixa, média baixa, média e alta. A ascensão social foi medida através de duas perguntas que questionavam se 0 entrevistado mudou de classe de 2004 até a data da entrevista e a qual classe pertencia antes.

Os resultados apresentaram evidências que a não-opinião diminui conforme a situação socioeconômica dos indivíduos passa para camadas mais privilegiadas. Os membros da classe média baixa expressaram menos não-opiniões que os da classe baixa, os da classe média menos que os da classe média-baixa, e os membros da classe média exibiram menos não-opiniões que a classe alta vezes sim, vezes não, mostrando pouca diferença entre elas nesse quesito. Assim, a não-opinião na classe média e alta foram sempre inferiores aos outros grupos e raramente significativas. Concluiu-se que a classe média se assemelha mais à classe alta que as mais baixas, e ao contrário do esperado, não apresenta mais opiniões 
indefinidas que as demais, prevalecendo a tese que os ganhos de acesso à informação decorrentes de uma melhora socioeconômica têm impacto na formação de opinião de forma linear. Os resultados quanto aos outros conceitos analisados não mostraram grandes diferenças entre as classes sociais e grupos de mobilidade social, tampouco apontaram as qualidades que seriam específicas aos setores intermediários ou aos grupos que apresentaram ascensão social. Concluiu-se que as classes médias compartilham visões de mundo com a classe alta, e ambas se diferenciam da classe baixa.

Não obstante os grandes avanços da literatura nacional para explicar variáveis atitudinais e comportamentais em relação à adesão aos valores democráticos, salvo melhor juízo, ainda não foram testadas o poder explicativo da mobilidade social e avaliações sociotrópicas sobre apoio às instituições democráticas e a tolerância política. Destarte, proponho exatamente a construir esse estudo.

\section{Resultados}

$O$ indicador de tolerância foi construído a partir de quatro baterias de perguntas presentes no survey de opinião pública do LAPOP de 2016; os anos anteriores desse questionário não contaram com as mesmas. A primeira bateria é sobre o direto dos cidadãos em geral de se manifestar; a segunda é concernente à participação política (votar, se manifestar, se candidatar a cargos públicos e aparecer na TV para discursar) de pessoas que falam mal da forma de governo; a terceira abarca dois direitos de pessoas homossexuais, e a última envolve três perguntas sobre participação política de um grupo que o indivíduo declarou gostar menos, entre militares, comunistas, defensores do aborto, petistas ou peessedebistas. Assim, o entrevistado deveria responder se concorda ou não que os grupos tenham cada um dos direitos descritos. O esquema abaixo ilustra essa relação:

\section{Quadro 2 - Questões usadas na construção do indicador de tolerância}

\begin{tabular}{|l|l|}
\hline Cidadãos em geral & Direito de se manifestar \\
\hline $\begin{array}{l}\text { Pessoas que falam } \\
\text { mal da forma de } \\
\text { governo }\end{array}$ & Direito de votar \\
& $\begin{array}{l}\text { Manifestações pacíficas } \\
\text { Candidatar-se para cargos } \\
\text { públicos }\end{array}$ \\
\hline
\end{tabular}




\begin{tabular}{|l|l|}
\hline & Discursar \\
\hline Homossexuais & Candidatar-se a cargos \\
& públicos \\
& Se casar \\
\hline \multirow{3}{*}{ Grupo menos } & Direito de votar \\
gostado & Fazer discurso público \\
& Concorrer a um cargo \\
& público \\
\hline
\end{tabular}

Fonte: Dados elaborados pelos autores com base em The Americas Barometer by the Latin American Public Opinion Project (LAPOP), www.LapopSurveys.org

O indicador desenvolvido a partir da concordância com direitos políticos pode variar de 10 a 100, de forma que quanto maior o valor pontuado pelo indivíduo, maior será seu o grau de tolerância. Assim, um indivíduo que não concorda que os grupos descritos tenham nenhuma dos direitos políticos abordados corresponde a nota 10 na escala de tolerância, ou seja, tem maior grau de intolerância, enquanto o indivíduo que concorda com todos os direitos descritos pontuaria o valor de 100 na escala, ou seja, o maior grau de tolerância. No resultado, a distribuição do indicador segue a aproximação de uma curva normal com média 62,3 , valor mínimo 11, máximo 100 e desvio padrão 19,1, como se observa no histograma abaixo:

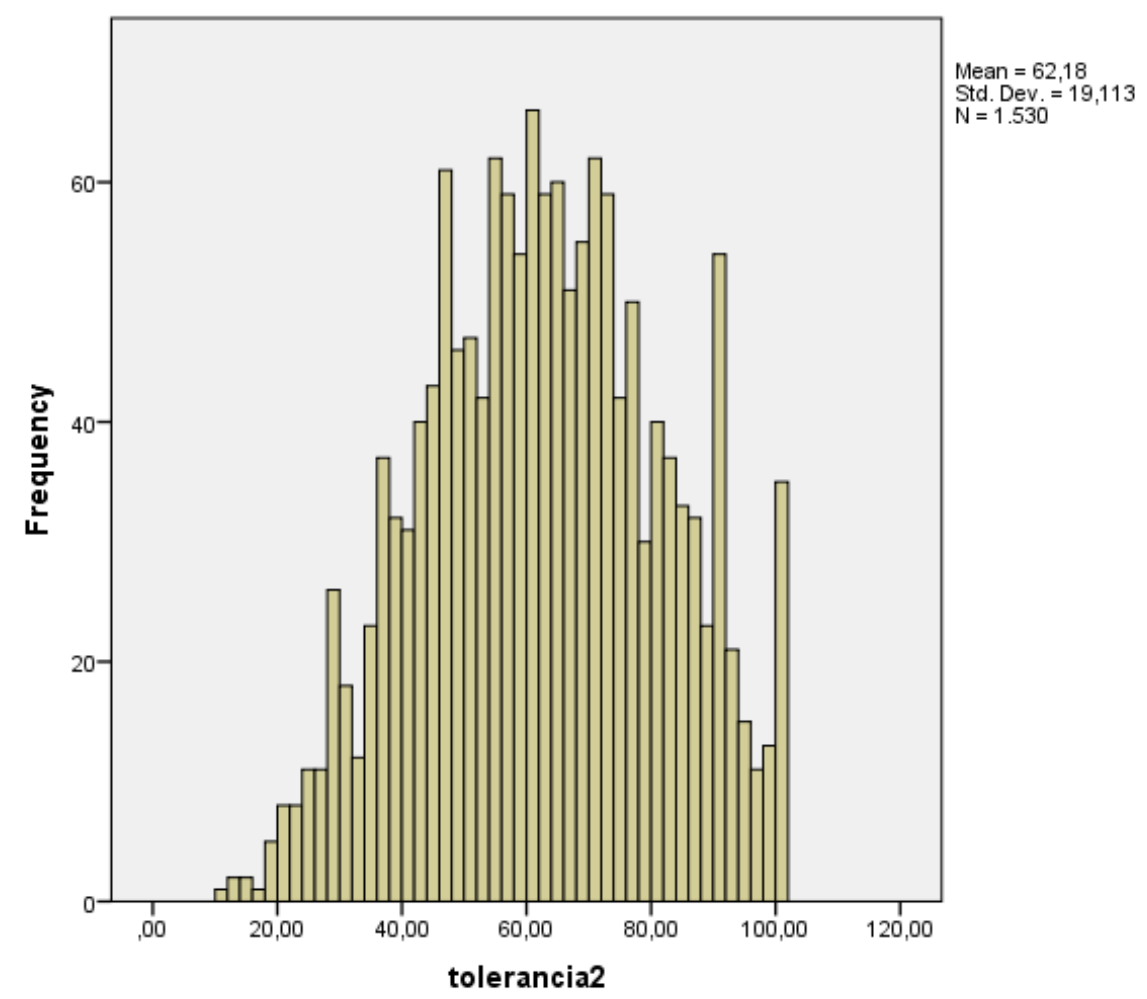


Fonte: Dados elaborados pelos autores com base em The Americas Barometer by the Latin American Public Opinion Project (LAPOP), www.LapopSurveys.org

Quanto à última bateria de questões, os resultados possibilitaram a elaboração do gráfico abaixo, que ilustra o "gosto" dos entrevistados quanto aos grupos analisados. As notas tendem a se agrupar nos extremos e no meio da escala de 1 a 10, na qual 1 significa "desgosto muito" e 10 significa "gosto muito". Entre os cinco grupos analisados, os mais gostados (receberam a nota 10 por maior número de entrevistados) são, ordenadamente, defensores do regime militar (com 17\% de aprovação máxima), defensores da legalização do aborto, petistas, e comunistas e PSDBistas empatados por último. A ordem dos grupos que mais receberam rejeição máxima, ou seja, atribuição de nota 1 , se dá com primeiramente defensores da legalização do aborto (48\% de desgosto), seguidos de comunistas, um empate entre PSDBistas e Petistas, e por fim, defensores do regime militar.

Figura 1 - "Gosto" em relação a grupos específicos

Desgosto/gosto com relação a grupos específicos

60,0

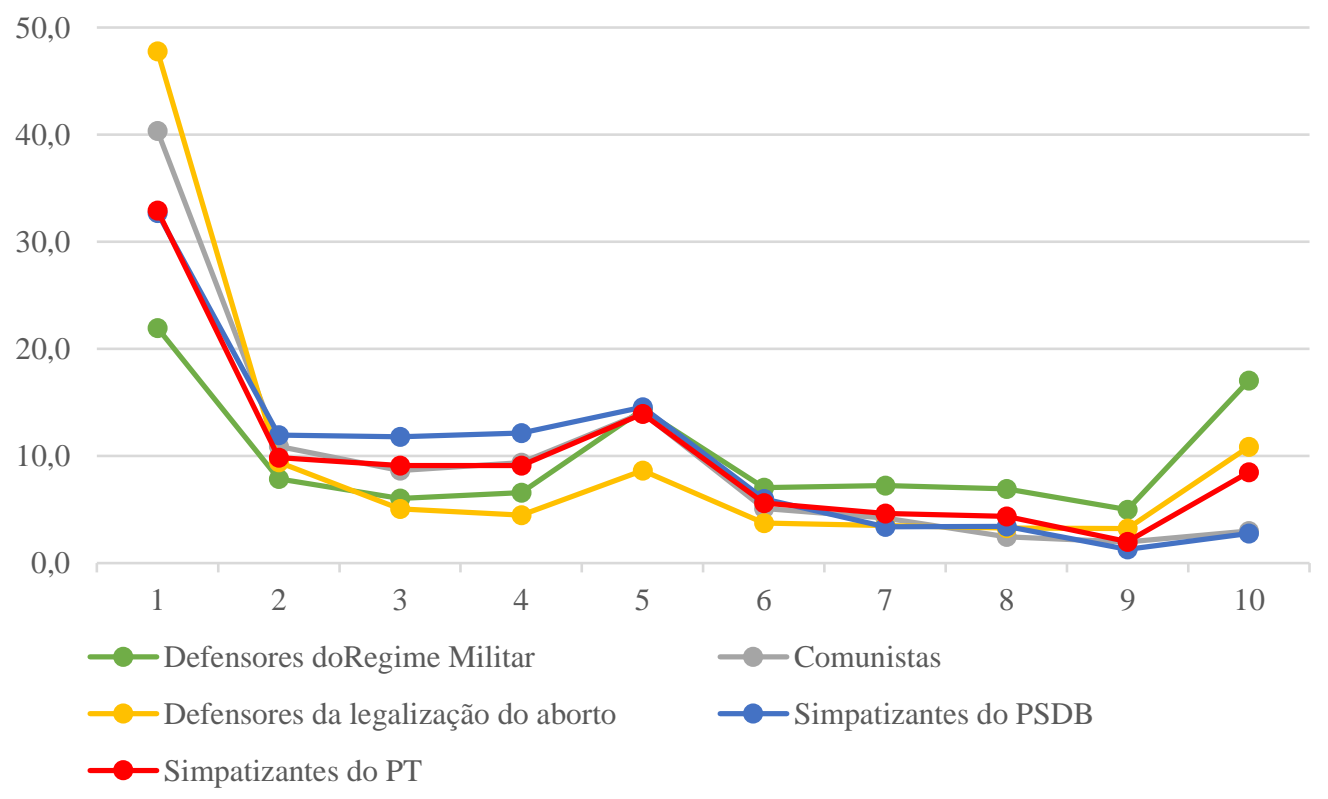

Dados elaborados pelos autores com base em The Americas Barometer by the Latin American Public Opinion Project (LAPOP), www.LapopSurveys.org. 


\section{Os modelos econométricos sobre tolerância política}

Foram construídos três modelos econométricos (OLS) no intuito de estimar o indicador de tolerância como variável dependente. Além das variáveis independentes avaliação egotrópica e sociotrópica da economia, que correspondem a hipótese central desse estudo, foram testados também as variáveis sexo, religião (católico, protestante tradicional, evangélico pentecostal, sem religião), anos de estudo, idade, macrorregião nacional, renda mensal habitacional, mobilidade social, carência de refeição, ser vítima de crime, mostrar insatisfação com a vida, desemprego, antipetismo e antipessedebismo, e posicionamento político como direta ou esquerda.

Tabela 1 - Condicionantes da tolerância política

\begin{tabular}{|c|c|c|c|c|c|c|}
\hline \multicolumn{3}{|c|}{$1^{\circ}$ Modelo } & \multicolumn{2}{|c|}{$2^{\circ}$ Modelo } & \multicolumn{2}{|c|}{$3^{\circ}$ Modelo } \\
\hline $\begin{array}{l}\text { Variáveis } \\
\text { independentes }\end{array}$ & $\mathrm{B}$ & Sig. & B & Sig. & B & Sig. \\
\hline (Constante) & 67.032 & .000 & 66.000 & .000 & 68.192 & .000 \\
\hline Mulher & 1.130 & .249 & 1.414 & .153 & 1.228 & .209 \\
\hline Católico & -.773 & .640 & -.465 & .780 & -.730 & .658 \\
\hline Protestante tradicional & -4.173 & .047 & -4.144 & .049 & -4.024 & .055 \\
\hline Evangélicos pentecostais & -4.921 & .008 & -4.724 & .011 & -4.582 & .013 \\
\hline Sem religiâo & .021 & .993 & .252 & .914 & .518 & .822 \\
\hline $\begin{array}{l}\text { Anos de escolaridade } \\
\text { formal }\end{array}$ & .894 & .000 & .883 & .000 & .926 & .000 \\
\hline Idade & -.295 & .000 & -.299 & .000 & -.297 & .000 \\
\hline Nordeste & -1.597 & .325 & -1.097 & .502 & -1.464 & .364 \\
\hline Centro Oeste & -1.184 & .511 & -1.195 & .509 & -.618 & .730 \\
\hline Sudeste & .657 & .663 & .989 & .516 & 1.120 & .456 \\
\hline Sul & -2.089 & .227 & -1.579 & .367 & -1.450 & .402 \\
\hline Renda familiar mensal & .124 & .284 & .158 & .189 & .197 & .098 \\
\hline Mobilidade ascendente & & & -1.461 & .210 & -1.592 & .168 \\
\hline Mobilidade descendente & & & .629 & .597 & .562 & .633 \\
\hline Socio_melhor & & & 2.196 & .266 & 1.885 & .336 \\
\hline Socio_pior & & & -1.016 & .437 & -.635 & .623 \\
\hline Egotrópica melhor & & & 1.643 & .246 & 1.688 & .227 \\
\hline Egotrópica pior & & & 1.197 & .295 & 1.269 & .260 \\
\hline Carencia de refeicao & & & .363 & .814 & .757 & .621 \\
\hline Vitima & & & 1.998 & .081 & 2.146 & .058 \\
\hline Insatisfação com a vida & & & -2.037 & .273 & -1.457 & .428 \\
\hline Desempregado & & & -2.796 & .325 & -2.646 & .346 \\
\hline
\end{tabular}




\begin{tabular}{|lrr|}
\hline Anti petista & -5.141 & .000 \\
\hline Anti pessedebista & -1.316 & .235 \\
\hline Esquerda & -.678 & .547 \\
\hline Direita & 1.601 & .196 \\
\hline
\end{tabular}

Dados elaborados pelos autores com base em The Americas Barometer by the Latin American Public Opinion Project (LAPOP), www.LapopSurveys.org

As variáveis religião (protestantes tradicionais e pentecostais), idade, vítima de crime e antipetismo foram negativas e estatisticamente significativas, ou seja, diminuem a tolerância política. Em outras palavras, a presença da variável protestante tradicional ou evangélico pentecostal pontua menos 4 ou 5 pontos na escala de tolerância do que membros de outras religiões e ateus ou agnósticos, tornando o indivíduo alguns pontos mais próximos da intolerância. Quanto à idade, cada ano a mais corresponde a menos 0,3 pontos na escala de tolerância. Considerando o efeito cumulativo, 10 anos a mais de idade trazem o indivíduo 3 pontos mais próximo da intolerância na escala, e em comparação, 40 anos de diferença de idade significam 12 pontos de distância na escala.

Apenas escolaridade (anos de estudo) foi positiva e estatisticamente significativa, ou seja, escolaridade aumenta a tolerância política mantidas constantes outras características do indivíduo. Cada ano de estudo tem impacto de 0.9 pontos na escala, e considerando efeito cumulativo, 10 anos de estudo tem impacto de 9 pontos.

\section{Conclusão}

Os resultados do estudo apontam que o grupo mais desgostado pela população é composto pelos defensores da legalização do aborto, que foi rejeitado com nota mínima por $48 \%$ dos entrevistados, enquanto o mais gostado é composto por defensores do regime militar, com 17\% de aprovação máxima.

A hipótese central do trabalho não foi comprovada, uma vez que não foram encontradas correspondências significativas entre o grau de tolerância e a avaliação da economia nacional ou pessoal. Porém, foram descobertas variáveis que exercem significativo impacto na tolerância política: foi negativo e estatisticamente significativo o antipetismo, idade, vítimas de crimes e religiosos das classificações evangélico pentecostal e protestante tradicional, ou seja, esses são os grupos mais intolerantes. Em contrapartida, maior escolaridade tende a aumentar o grau de tolerância dos indivíduos. 


\section{Referências bibliográficas}

APARECIDO RIBEIRO, Ednaldo; BORBA, Julian; FUKS, Mario. Contexto democrático, escolaridade e tolerância política na América Latina. Investigación Social Aplicada, p. 11, 2019.

BORBA, Julian. Cultura política, ideologia e comportamento eleitoral: alguns apontamentos teóricos sobre o caso brasileiro. Opinião pública, v. 11, n. 1, p. 147168, 2005.

DE SOUZA CARREIRÃO, Yan. A decisão do voto nas eleições presidenciais brasileiras. FGV Editora, 2002.

FUKS, Mario et al. Qualificando a adesão à democracia: quão democráticos são os democratas brasileiros?. Revista Brasileira de Ciência Política, n. 19, p. 199-219, 2016.

GIMENES, É. R. Eleitores E Partidos Políticos Na América Latina. Curitiba: APPRIS, 2017.

INGLEHART, Ronald. A REVOLUÇÃO SILENCIOSA NA EUROPA: MUDANÇA INTERGERACIONAL NAS SOCIEDADES PÓSINDUSTRIAIS. Revista de Sociologia e Política, v. 20, n. 43, 2012.

INGLEHART, Ronald; WELZEL, Christian. Modernização, mudança cultural e democracia: a sequência do desenvolvimento humano. Francis, 2005.

LEVITSKY, S.; ZIBLATT, D. (2018). Como as democracias morrem. Zahar.

MOISÉS, J. A. Cultura Política, Instituições e Democracia - lições da experiência brasileira. Revista Brasileira de Ciências Sociais, vol. 23, nº 66, p.11-44, 2008.

NICOLAU, Jairo. Determinantes do voto no primeiro turno das eleições presidenciais brasileiras de 2010: uma análise exploratória. Opinião Pública, v. 20, n. 3, p. 311-325, 2014.

O'DONNELL, Guillermo. Accountability horizontal e novas poliarquias. Lua nova, v. 44, n. 98, p. 27-54, 1998.

PEIXOTO, Vitor; RENNÓ, Lucio. Mobilidade social ascendente e voto: as eleições presidenciais de 2010 no Brasil. Opinião Pública, v. 17, n. 2, p. 304-332, 2011.

PRZEWORSKI, A.; CHEIBUB, J. A.; LIMONGI, F. Democracia e cultura: uma visão não culturalista. Lua Nova, v.58, p. 9-35, 2003.

PRZEWORSKI, Adam et al. O que mantém as democracias. Lua Nova, v. 40, n. 41, p. 113-135, 1997.

RENNÓ, Lucio; TURGEON, Mathieu. A Psicologia Política das Classes Sociais no Brasil: Atributos das Atitudes Políticas por Estratificação e Mobilidade Social. Dados- Revista de Ciências Sociais, v. 59, n. 1, p. 11-51, 2016.

RIBEIRO, E.; BORBA, J. Participação e pós-materialismo na América Latina. Opinião Pública, v. 16, n. 1, p. 28-64, 2010.

RIBEIRO, Ednaldo Aparecido. Valores pós-materialistas e adesão normativa à democracia entre os brasileiros. Revista Debates, v. 2, n. 2, p. 103-133, 2008. 
RIBEIRO, Ednaldo; CARREIRÃO, Yan; BORBA, Julian. Sentimentos partidários e atitudes políticas entre os brasileiros. Opinião Pública, v. 17, n. 2, p. 333-368, 2011. SCANLON, Thomas M. A dificuldade da tolerância. Novos Estudos-CEBRAP, n. 84, p. $31-45,2009$.

SILVA, Thiago Moreira da. Para além de esquerda e direita: a multidimensionalidade das crenças no Brasil contemporâneo (1989-2014). 2017.

VEIGA, Luciana Fernandes. O partidarismo no Brasil (2002/2010). Opinião Pública, v. 17, n. 2, p. 400-425, 2011.

VEIGA, Luciana Fernandes. Os partidos brasileiros na perspectiva dos eleitores: mudanças e continuidades na identificação partidária e na avaliação das principais legendas após 2002. Opinião pública, v. 13, n. 2, p. 340-365, 2007. 